\title{
The physics of crowds
}

\section{Once social scientists inspired physicists. Now the reverse is true.}

\section{Critical Mass: How One Thing Leads to Another \\ by Philip Ball \\ William Heinemann: 2004. 644 pp. $£ 25$ \\ To be published by Farrar, Straus and \\ Giroux in the US}

\section{Steven Strogatz}

Psychohistory is a remarkably accurate theory of humans' collective behaviour. It predicts the rise and fall of political movements and empires, and even the sweep of civilization itself. Like the calculations at the root of the insurance industry, it is a fundamentally statistical science, valid only for groups large enough for the vagaries of individuals to average out.

Of course, this theory is the stuff of science fiction, as readers of Isaac Asimov's Foundation series will recognize. But in the past decade or two, the dream of psychohistory - although admittedly in a much more modest form - has seduced a motley crew of physicists, complex-systems theorists and social scientists. Borrowing the tools of statistical mechanics and nonlinear dynamics, and armed with unprecedented computer power and huge data sets, they have re-examined some classic puzzles about human group behaviour and its social, economic and political ramifications. These include the causes of boom-bust cycles in the economy; the long-tailed distribution of wealth; the stampedes of panicked crowds; how altruism can emerge in a group of selfish individuals; and the infuriating waves of congestion that can clog traffic on an otherwise open highway. The goal, in short, is to develop a physics of society.

In his fascinating new book Critical Mass, Philip Ball tells the story of this research in a comprehensive and often captivating way. But what I liked best about the book is that Ball delves far beyond today's headlines. In particular, I was surprised to learn that this intellectual thread has a long history that is the exact reverse of what is generally supposed. Statistical physics did not spawn social physics; it was the other way around.

In the 1870s, when James Clerk Maxwell was developing the kinetic theory of gases, he knew it would be impossible to track the motion of countless particles ricocheting in a hot gas. But he drew hope from an earlier generation of social statisticians, who had demonstrated that enormous populations of people - who were individually every bit as capricious as gas molecules - could nevertheless display precise regularities. After reading Henry Thomas Buckle's History of Civilization in England, which espoused this

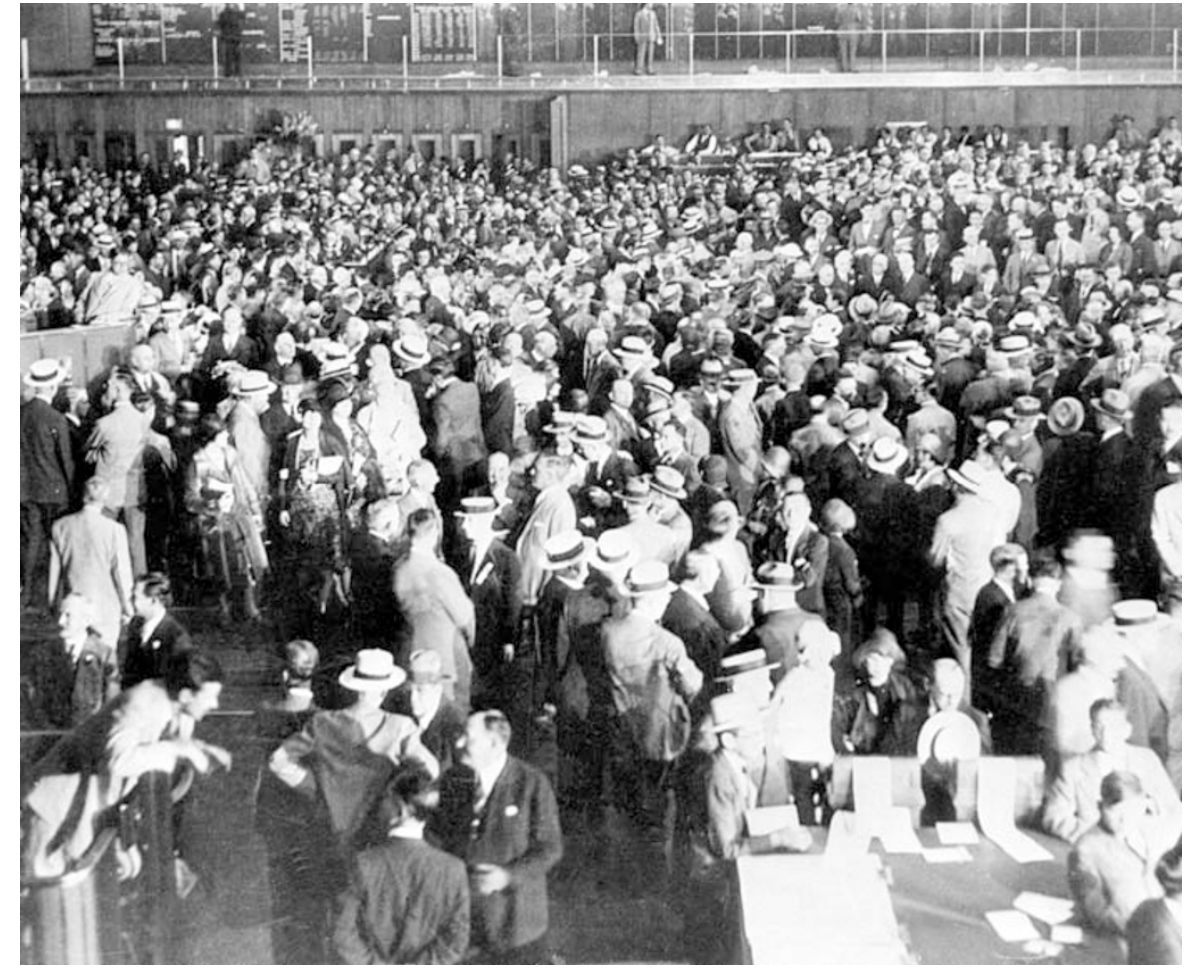

Human interest: physicists have tried to explain processes from the action of crowds to the economy.

statistical point of view, Maxwell wrote: "Those uniformities which we observe in our experiments with quantities of matter containing millions and millions of molecules are uniformities of the same kind as those explained by Laplace and wondered at by Buckle arising from the slumping together of multitudes of causes each of which is by no means uniform with the others."

Even the term 'statistics' originated in this movement to quantify social phenomena. In 1749, the German scholar Gottfried Achenwall suggested it as a name for the numerical study of the states of society, which were just beginning to be summarized in terms of death rates, birth rates and other population measures.

Critical Mass is full of historical tidbits like this. Ball particularly enjoys setting the record straight on matters of nomenclature, priority and the like. Thus we learn that Adam Smith argued that a hidden hand, not an invisible one, ruled free markets, and that Maxwell's demon was so named by William Thomson, much to the chagrin of the devoutly religious Maxwell. Maxwell had described his hypothetical creature more lovingly, as "a very observant and neat-figured being”.

This book is impressively clear and breathtaking in scope. Ball explains the basics of every subject he treats, from the political upheavals in seventeenth-century England that gave rise to Thomas Hobbes' vision of utopia, to van der Waals' theory of phase transitions between liquids and gases. Furthermore, unlike so many recent books about complexity theory, this one sets everything in proper historical context, and does not oversell its ideas. Ball even draws on pop literature. For example, to illustrate the abruptness and long-range character of phase transitions, he invokes Kurt Vonnegut's Grand Ah-Whoom from Cat's Cradle, in which a shard of ice-nine seeds the freezing of all the world's oceans.

On the other hand, I did find Ball's treatment of the discovery process a bit disembodied. Or to say that more positively, this is a book about ideas, not about scientists and their struggles. You won't learn much about how the pioneers in this field made their breakthroughs, or about what drove them, or what they were like. But perhaps that would be asking too much. The book is already massive, and its heft made me wonder if its title were a pun.

Speaking of which, the title Critical Mass: How One Thing Leads to Another struck me as uncannily (or perhaps intentionally?) close to the title of Malcolm Gladwell's recent bestseller, The Tipping Point: How Little Things Can Make a Big Difference. Both books deal with collective phenomena in 
society, or what Gladwell calls social epidemics, but the resemblance ends there. Gladwell's book is fluffy and full of entertaining anecdotes, but is often unconvincing. Ball's is substantial, impeccably researched and generally more persuasive. For anyone who would like to learn about the intellectual ferment at the surprising junction of physics and social science, Critical Mass is the place to start.

Steven Strogatz is in the Center for Applied Mathematics and the Department of Theoretical and Applied Mechanics, Cornell University, Ithaca, New York 14853-1503, USA.

\section{Chemistry between man and insect}

\section{For Love of Insects}

by Thomas Eisner

Harvard University Press: 2003. 464 pp.

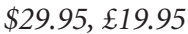

\section{Jeremy N. McNeil}

Chemical ecology, the study of how natural chemicals affect the interactions between organisms, has become a well-recognized discipline in the past 50 years. A number of remarkable scientists have moulded the field, many of whom mix their love of science with an appreciation for the arts and life in general, making them true Renaissance individuals. Thomas Eisner, author of For Love of Insects, is one such person: as well as a world-renowned scientist and teacher, he is an excellent photographer and talented musician.

For Love of Insects is not your typical biological text integrating information from the literature on a topic. Instead this book is a series of vignettes. Each of the ten chapters discusses a different chemical ecology project that Eisner and his colleagues have carried out over the past 40 years. The book is well written and beautifully illustrated with colour photographs, the majority taken by the author. I would strongly recommend this book for several reasons.

First, each chapter introduces the reader to different facets of the wonderful world of insects. We learn how many insects defend themselves by spraying aggressors with noxious secretions, how they hit their target, and how they keep themselves from suffering the effects of the compounds they deploy. We discover that insects may produce their own compounds or get them from their food. In some instances, females may receive them from males during mating, and the quantity of a male's defence compounds may determine whether he gets a mate.

Some insects defend themselves with their excrement, or disguise themselves with flower petals. Others adopt a strategy by

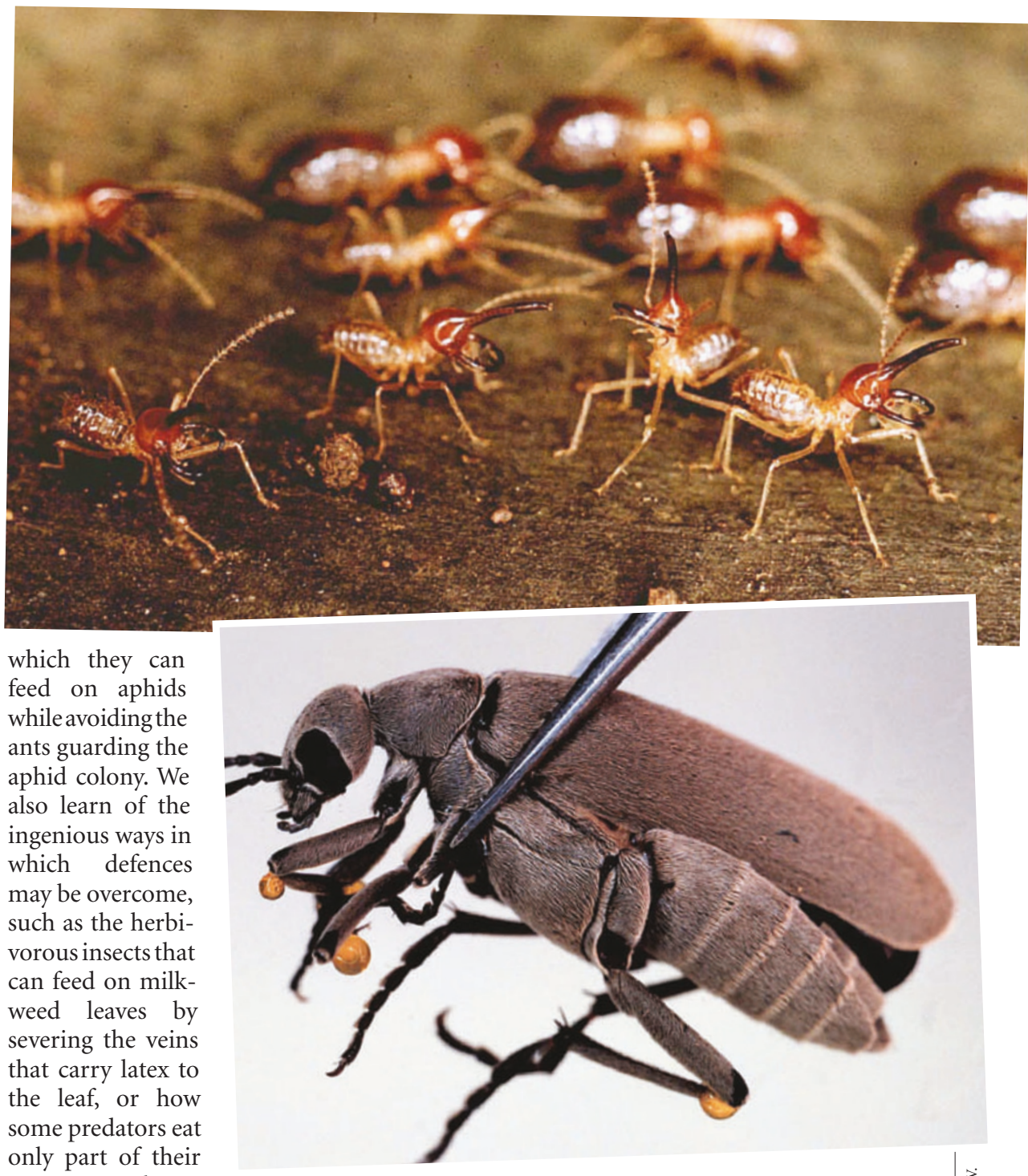

only part of their prey to avoid toxins. And if one is on the lookout for research projects, Eisner provides some pointers. For example, what is the role of the second soldier caste in the termite Nasutitermes exitiosus? Are blister beetles the only source of cantharidin, a defence chemical that is better known as the pre-Viagra Spanish fly, for cantharidiphilous insects?

Second, the author shows what is needed to produce first-class ecological research. Like Eisner, one must combine keen observation with a desire to understand the phenomena observed. Furthermore, one needs to design elegant and simple experiments to answer 'why?' and 'how?' questions. This underscores the importance of creative thinking - a timely reminder in the postgenomic world that good science is not just a matter of fancy equipment and sophisticated techniques.

Collaboration is another key ingredient. Eisner's research into the bombardier beetle, an insect that defends itself with boiling secretions - rather like a castle's soldiers pouring hot oil on the heads of besiegers spanned more than 30 years. He credits his graduate students Daniel Aneshansley and
Jeff Dean and 17 others who identified and acquired biological material, provided insights into chemical defences and the role of benzoquinones in particular, and worked out how to photograph the spectacular defensive behaviour.

Two collaborators stand out. Eisner has a long-standing association with chemist Jerry Meinwald, who identified many of the compounds involved in the interactions observed. The other is his wife, Maria Eisner, who took the excellent scanning electron micrographs found in this book and in many of their publications. Both share Eisner's love of music, and I have heard meetings.

Throughout the text one is reminded of the pleasure that the author derives from discovery. Anyone reading this book will themselves embark upon a journey of discovery and come to share, if only at arm's length, Tom's love of insects and the wonders of nature.

Jeremy N. McNeil is in the Department of Biology, University of Western Ontario, London,

Ontario N6A 5B7, Canada. Tom and Jerry perform at several scientific 